\title{
ВЗАИМОСВЯЗЬ НАУКИ И ОБРАЗОВАНИЯ КАК ФАКТОР ИННОВАЦИОННОГО ЭКОНОМИЧЕСКОГО РАЗВИТИЯ
}

\author{
(c) 2020 Сажина М.A. \\ доктор экономических наук, \\ профессор кафедры экономики инновационного развития \\ факультета государственного управления \\ Московский государственный университет имени М. В. Ломоносова, Россия, Москва \\ E-mail: M_Sazhina@spa.msu.ru \\ SPIN-код РИНЦ: 4093-5216 \\ (c) 2020 Ильина А.А. \\ аспирантка кафедры экономики инновационного развития \\ факультета государственного управления \\ Московский государственный университет имени М.В. Ломоносова, Россия, Москва \\ E-mail: IlinaAA@spa.msu.ru \\ SPIN-код РИНЦ: 8616-0487
}

Статья посвящена проблемам взаимосвязи современного образования и науки на пути к инновационному развитию национальной экономики России. Концентрация усилий в области поддержки интеллектуального капитала благодаря кооперационным связям различных научных, образовательных, государственных и производственных структур является ключевым направлением развития инновационной экономики. Отдельное внимание уделено современной системе высшего образования, проанализированы тенденции развития в рамках Болонского процесса, указаны основные проблемы отсутствия полноценного диалога научного и образовательного компонентов. Раскрывается взаимосвязь науки и образования, показано, что наряду с научно-техническим прогрессом на инновационный экономический рост влияет и научно-образовательный прогресс, предлагается авторское определение данного термина. Блок-схема, предложенная в статье, раскрывает направления развития научно-образовательной сферы в России. В качестве основных методов в статье используются статистический, логический и дедуктивный метод, анализ и синтез. Делается вывод, что инновационное экономическое развитие прямым образом зависит от налаживания системы согласования науки с образованием, а существующие проблемы в области высшего образования являются тормозом к установлению подобных связей.

Ключевые слова: научно-образовательная сфера, инновационное экономическое развитие, взаимосвязь науки и образования, программа аспирантуры, интеллектуальный капитал, научнообразовательный прогресс.

Происходящая глобальная трансформация финансово-экономических, политических, технологических процессов не только бросает вызов мировой системе хозяйственных отношений, но и требует активации механизма развития интеллектуального капитала, задействованного сегодня в различных видах деятельности национальной экономики.

Интеллектуальный капитал - это, прежде всего, важнейшая нематериальная составляющая обеспечения востребованности национальной экономики в долгосрочной перспективе. Однако, эта нематериальная составляющая требует колоссальных материальных вложений для инновационного экономического развития государства. Сосредоточение таких вложений в нестабильный для мировой экономики период требуется именно в научно-образовательной сфере, а обеспечение лидирующих позиций в этом направлении невозможно без производства новых знаний, где человек играет главенствующую роль.

Идеи классиков экономической мысли К. Маркса, А.Смита, У.Петти, Д.Рикардо, заложенные в основу концепции человеческого капитала, о преимущественной роли человеческих 
способностей и образования в национальном богатстве и экономическом развитии общества $[1,5,10]$ даже в эпоху масштабного развития искусственного интеллекта остаются востребованными, а категории «интеллектуальный капитал», «человеческий капитал» наполняются новым качественным смыслом.

Как метко отмечает профессор МГУ имени М. В. Ломоносова М.А. Сажина: «Современный человек является не просто «рабочей силой», «винтиком» экономики; он - ее интеллектуальное начало и универсальный двигатель в современных динамично меняющихся условиях» [9]. В свою очередь, знания в современной экономике инновационного типа охватывают широкий спектр разнообразных способностей человека, а приумноженные знания влияют не только на их количество, но и качество [3].

Исходя из этого, можно сформировать цепочку зависимости прорывного экономического развития от наращивания потенциала интеллектуального капитала: исследования рыночной конъюнктуры - планирование инноваций-государственное планирование в сфере науки и образования - финансовое обеспечение научно-образовательной деятельности генерация новых знаний - подготовка квалифицированных кадров с помощью внедрения актуальных образовательных программ -проведение фундаментальных и прикладных исследований - производство новых продуктов, услуг и технологий (инноваций) - коммерциализация инноваций - полное технологическое оснащение реального сектора экономики - производство необходимой отечественной продукции - выход на устойчивый рост ВВП - инновационное экономическое развитие.

Данная схема свидетельствует о том, как протекающие технологические процессы в инновационной сфере находят свое развитие и дальнейшее обновление благодаря стратегическому видению рыночных изменений, потребностей в квалифицированном персонале в стратегически важных отраслях промышленности, насколько приоритетна слажено выстроенная система планирования и поддержки научнообразовательной сферы. Ключевым механизмом в создании инноваций является организация непрерывного потока знаний, выраженного в следующих формах: передача знаний в процессе обучения, трансфер научно-технической информации из университетов в реальный сек- тор экономики, коммерциализация результатов интеллектуальной деятельности, реализация национальных и транснациональных высокотехнологичных проектов [8].

Рассмотрим основные проблемы взаимосвязи науки и образования. В России, да и в мире в целом, продолжает назревать широкая дискуссия о тесной связи научного и образовательного компонентов, о целесообразности интеграции двух важнейших социально-экономических институтов. Согласно Берлинской конференции, на которой Россия присоединилась к Болонскому процессу осенью 2003 года [11], ключевой частью высшего образования выступают научные исследования, что объясняет принцип единства науки и образования. Унификация образовательных параметров и их адаптация под научно-исследовательскую стезю, безусловно, имеет свои преимущества: стимулирование научно-исследовательской деятельности, повышение роли науки в классических университетах, воспроизводство творческого потенциала студентов. Все это помогает решению задач, призванных обеспечить конкурентоспособность квалифицированных специалистов, заполнить ими мировой рынок труда, а также заложить основы для научно-технического прогресса.

Тем не менее, в настоящее время прослеживается процесс квазигармоничного сосуществования системы высшего образования и научноисследовательской деятельности. Современное разделение системы высшего образования на три ступени имеет свои нюансы, что особенно касается воплощения данной реформы в России:

- Во-первых, несмотря на заявление о программе бакалавриата, как о самодостаточной ступени образования, работодатели, в большинстве своем, до сих пор имеют представление о весьма тривиальном багаже знаний, умений и навыков, которые можно освоить за 4 года обучения (исключение составляют некоторые медицинские и педагогические профили обучения);

- Во-вторых, третьей ступенью высшего образования является аспирантура. Подразумевается, что программа аспирантуры является продолжением высшего образования. Сейчас же программа аспирантуры превратилась в «фабрику подготовки аспирантов» [6], она не функционирует в качестве научной программы и, как следствие, абсолютно не оправдывает себя. Недаром сказал известнейший российский историк, профессор Московского университе- 
та В.О.Ключевский: «Науку часто смешивают с знанием. Это глубокое недоразумение. Наука есть не только знание, но и сознание, т.е. умение пользоваться знанием» [4];

- В-третьих, третьей ступенью высшего образования является и докторантура. Получается, что обладатель ученой степени доктора наук освоил третью по счету программу образования, а научно-исследовательская деятельность в личном деле потенциального доктора наук несет посредственный характер;

- В-четвертых, сотрудничая с ведущими европейскими системами в рамках Болонского процесса, ученые содействуют необходимым европейским воззрениям в высшем образовании и в проведении научных исследований. Параллельно тому студентам, научнопедагогическому составу приходится делиться с зарубежными коллегами собственными наработками, накопленными многолетним трудом со времен советской науки. Возрастает угроза потерять ценные и уникальные достижения отечественного высшего образования и науки, обостряется и без того висящая в воздухе проблема интеллектуальной собственности.

Остановимся подробнее на специфических чертах современной программы аспирантуры в России.

На сегодняшний день программа аспирантуры в Российской Федерации является единственным проводником выпускников в науку и представляет собой гибрид из образовательного процесса и научно-исследовательской деятельности (Таблица 1).

Из данных таблицы видно, что образовательный компонент превалирует над научным, а основные недостатки данного явления очевидны:

- Половина времени обучения в аспирантуpe - освоение учебных дисциплин, но и научно- исследовательскую работу требуется проводить параллельно с учебным процессом;

- Чрезмерное внимание уделяется аттестации аспирантов - без неоднократного своевременного закрытия «хвостов» по учебным дисциплинам аспирант теряет возможность получения и без того низкой академической стипендии (на уровне стипендии студентов программы бакалавриата и магистратуры);

- Образовательный процесс в аспирантуре почти ничем не отличается от образовательного процесса на предыдущих ступенях образования, а дисциплины порой дублируются или их содержание мало чем отличается от уже освоенных ранее;

- Рост требований научных изданий не только снижает количество российских соискателей ученой степени наук, но и тем самым, не отражает квалификацию соискателя и качество программы аспирантуры в целом.

Отсюда можно сделать вывод, что программа аспирантуры сегодня имеет недостаточную научную составляющую, падает востребованность этой программы даже в ведущих образовательных организациях высшего образования из-за строго регламентированной учебной деятельности и тернистого пути к возможности заниматься научными исследованиями, осуществлять преподавательскую деятельность.

Кроме того, динамика основных показателей деятельности аспирантуры оставляет желать лучшего. Таблица 2 наглядно демонстрирует, насколько критично ежегодно снижается численность аспирантов в период 2010-2018 гг. в организациях, осуществляющих программу аспирантуры.

В связи с этим, сомнительной является целесообразность включения программы аспирантуры в третью ступень высшего образования.

Таблица 1. Особенности программы аспирантуры в контексте образовательного и научного компонентов

\begin{tabular}{|c|c|}
\hline $\begin{array}{c}\text { Образовательный компонент } \\
\text { программы аспирантуры }\end{array}$ & $\begin{array}{c}\text { Научный компонент } \\
\text { программы аспирантуры }\end{array}$ \\
\hline $\begin{array}{l}\text { Освоение обязательных учебных дисциплин } \\
\text { согласно выбранной специальности }\end{array}$ & Подготовка научно-квалификационной работы \\
\hline Дисциплины по выбору & $\begin{array}{l}\text { Добровольная защита диссертации на соискание } \\
\text { ученой степени кандидата наук }\end{array}$ \\
\hline Зачетная и экзаменационная сессия & $\begin{array}{l}\text { Высокие требования для публикации основных } \\
\text { научных результатов диссертации на соискание } \\
\text { ученой степени кандидата наук }\end{array}$ \\
\hline Академический рейтинг аспирантов & \\
\hline
\end{tabular}

Источник: Составлено авторами. 
Таблиц̧а 2. Основные показатели деятельности аспирантуры [7]

\begin{tabular}{|c|c|c|c|c|c|}
\hline Годы & $\begin{array}{c}\text { Число органи- } \\
\text { заций, ведущих } \\
\text { подготовку аспи- } \\
\text { рантов }\end{array}$ & $\begin{array}{c}\text { Численность аспи- } \\
\text { рантов (на конец } \\
\text { года), человек }\end{array}$ & $\begin{array}{c}\text { Прием в аспиран- } \\
\text { туру, человек }\end{array}$ & $\begin{array}{l}\text { Выпуск из аспи- } \\
\text { рантуры, человек }\end{array}$ & $\begin{array}{c}\text { в том числе с } \\
\text { защитой диссер- } \\
\text { тации }\end{array}$ \\
\hline 1992 & 1296 & 51915 & 13865 & 14857 & 3135 \\
\hline 2000 & 1362 & 117714 & 43100 & 24828 & 7503 \\
\hline 2005 & 1473 & 142899 & 46896 & 33561 & 10650 \\
\hline 2010 & 1568 & 157437 & 54558 & 33763 & 9611 \\
\hline 2014 & 1519 & 119868 & 32981 & 28273 & 5189 \\
\hline 2015 & 1446 & 109936 & 31647 & 25826 & 4651 \\
\hline 2016 & 1359 & 98352 & 26421 & 25992 & 3730 \\
\hline 2017 & 1284 & 93523 & 26081 & 18069 & 2320 \\
\hline 2018 & 1223 & 90823 & 27008 & 17729 & 2198 \\
\hline \multicolumn{6}{|c|}{ Научно-исследовательские организации } \\
\hline 1992 & 443 & 36747 & 11238 & 9532 & 2213 \\
\hline 2000 & 565 & 100212 & 37025 & 21015 & 6630 \\
\hline 2005 & 640 & 122913 & 40319 & 28755 & 9641 \\
\hline 2010 & 748 & 139908 & 48748 & 29268 & 8854 \\
\hline 2014 & 698 & 107083 & 29700 & 24836 & 4770 \\
\hline 2015 & 661 & 97847 & 28285 & 22971 & 4318 \\
\hline 2016 & 611 & 87180 & 23281 & 22917 & 3379 \\
\hline 2017 & 599 & 82633 & 22749 & 15753 & 2063 \\
\hline 2018 & 585 & 79583 & 23580 & 15546 & 1977 \\
\hline \multicolumn{6}{|c|}{ Организации дополнительного профессионального образования } \\
\hline 2010 & 11 & 593 & 155 & 160 & 28 \\
\hline 2014 & 16 & 610 & 155 & 106 & 22 \\
\hline 2015 & 14 & 561 & 173 & 127 & 20 \\
\hline 2016 & 15 & 591 & 191 & 121 & 20 \\
\hline 2017 & 15 & 659 & 199 & 107 & 10 \\
\hline 2018 & 14 & 621 & 150 & 133 & 10 \\
\hline \multicolumn{6}{|c|}{ Иные организации } \\
\hline 2018 & 6 & 92 & 25 & 11 & 2 \\
\hline
\end{tabular}

Аспиранты, выбравшие научно-педагогический путь, имеют предостаточный багаж знаний и навыков по прошествии нескольких лет обучения на предыдущих ступенях высшего образования. Чего действительно не хватает для усиления роли научной деятельности и формирования высшего научного кадрового сообщества (а не среднестатистических специалистов с очередным дипломом), так это полномасштабного сотрудничества с производственными предприятиями, научно-исследовательскими институтами. Работа в этом направлении требуется не только для помощи в обеспечении дальнейшего трудоустройства аспирантов, но и для того, чтобы:

- задействовать молодые научные кадры в проведении научно-исследовательской деятельности, познакомить их с современными технологиями проведения исследований;

- включить получение практических навыков научно-исследовательской деятельности в обязательную программу подготовки аспирантов;

- дать возможность аспирантам дополнить научно-квалификационную работу данными, полученными в ходе научной практики, что, несомненно, качественно повысит уровень диссертационных исследований;

- позволить руководству программ аспирантуры в различных образовательных организациях производить обмен опытом между аспирантами для проведения совместных 
научно-практических мероприятий (возможность повысить статус низкорейтинговых образовательных организаций);

- активнее приглашать лучших аспирантов на мастер-классы в научно-исследовательские учреждения, а также в качестве спикеров на открытые лекции для школьников и студентов с акцентом на популяризацию научной деятельности.

Поэтому научная аспирантура - это будущий центр подготовки научных работников, реализующих потенциал научной сферы государства и позволяющий получить новые дополнительные стимулы развития наукоемких отраслей национальной экономики. Аспирантура будущего - это связующее звено между образованием и наукой, но ориентированное не на продолжение получения профессионального образования, а на непрерывное развитие собственных компетенций, актуализацию уже освоенных навыков.

На основании выше предложенного программу аспирантуры в России следует рассматривать в качестве основного рычага повышения конкурентоспособности научно-образовательной сферы, а самих аспирантов - главными носителями интеллектуального капитала.

Взаимосвязь науки и образования в современной экономике обусловлена определенными факторами:

- Наука не может эффективно развиваться при низком качестве образования. Совместное наращивание новых знаний и генерация идей позволит увеличить отдачу от вложения государственных средств в науку;

- Наука «подпитывает» производство и образование новыми открытиями, производство является источником инноваций и главным инвестором в научные разработки, а образование, в свою очередь, обеспечивает подготовку кадров для науки и производства;

- Стимулирование научно-исследовательской деятельности в образовательных организациях повышает способность молодого поколения творчески мыслить, закладывает стремление к разработке собственных изобретений. Тем самым, сформированное научно-техническое творчество способствует инновационному развитию, технологическое образование создает положительный эффект в экономике.

Это подтверждает актуальную мысль о том, что образование и наука без взаимной интегра- ции и тесного взаимодействия с реальным сектором экономики теряют дееспособность и становятся менее самодостаточными [2].

Поэтому сегодня можно говорить не только о воздействии научно-технического прогресса, но и научно-образовательного прогресса на экономический рост.

В этом смысле научно-образовательный прогресс следует понимать как качественное изменение совокупности процессов: связанных с активным проведением и представлением фундаментальных и прикладных исследований; находящихся в состоянии постоянного появления и движения новых знаний; обеспечивающих высокий уровень социализации и творческих способностей личности для увеличения доли национального интеллектуального капитала и поддержания конкурентоспособности экономики государства.

Благодаря интеллектуальному капиталу, формируются предпосылки дальнейшего использования результатов научно-образовательного прогресса как ценных ресурсах национальной экономики.

Говоря о состоянии научно-образовательной сферы в инновационной экономике, необходимо отметить основные тенденции развития научно-образовательной сферы в России. Сгруппируем существующие тренды в тематические блоки (Рисунок 1).

Каждый элемент в предложенной блок-схеме олицетворяет квинтэссенцию интеграционных процессов в области науки и образования:

- Административный блок включает в себя, прежде всего, государственные инструменты поддержки развития науки и образования: нормативно-правовое регулирование, постановка и решение задач по формированию и развитию научной и образовательной инновационной инфраструктуры благодаря совместным усилиям с региональными структурами власти. В данном направлении государство выступает основным организатором необходимой модернизации научно-образовательной среды;

- Институциональный блок «живет» посредством государственных, общественных и бизнес- инициатив по созданию и поддержке различного вида научных центров, автономных некоммерческих организаций, образовательных фондов, которые в своей совокупности составляют ядро основных двигателей научнообразовательного прогресса и содействуют го- 


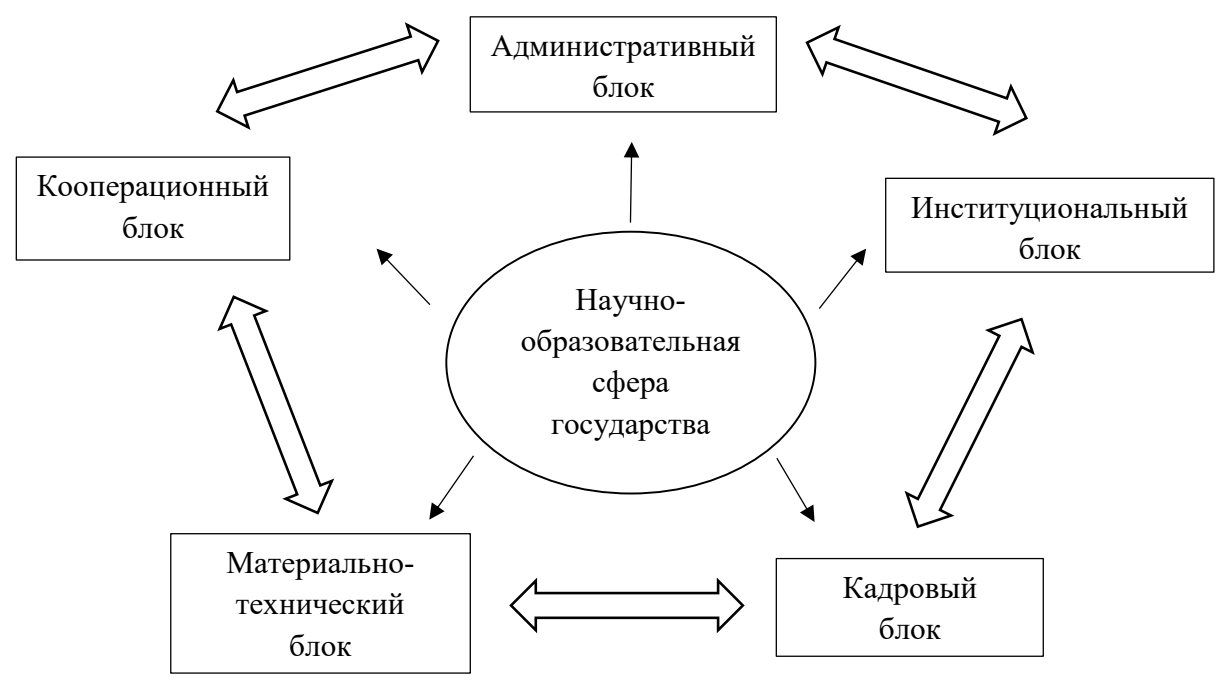

Puc. 1. Развитие научно-образовательной сферы (по направлениям) Источник: Составлено авторами.

сударству в реализации и совершенствовании образовательных программ в целях подготовки специалистов мирового класса;

- Так как особым достоянием национальной экономики является интеллектуальный капитал, то зарождение и поддержка кадрового потенциала становится первоочередной мерой в созданных учреждениях науки и образования при обязательном условии обновления и адаптации современных программ обучения и научно-исследовательской деятельности. Данное направление характеризуется своим, особым лозунгом - «обмен знаниями - это прочный фундамент для движения к инновациям в условиях трансформации современной экономики»;

- Каким образом современная система образования и научная деятельность должны отвечать вызовам трансформирующейся экономики? Без материально-технической базы, а именно, образовательных и научных учреждений мирового уровня и необходимых инновационных инфраструктурных объектов, современного специализированного оборудования для комфортной учебной и научно-исследовательской деятельности данную задачу решить невозможно;

- Когда все основные условия для развития научно-образовательной среды созданы, заключительным моментом является стремление избежать изолированности, способствовать укреплению кооперационных связей между образовательными структурами, научными учреждениями, организациями реального сектора экономики для достижения максимальных результатов национального масштаба. Результатом данного сотрудничества выступают совместное проведение профильных мероприятий, коллективное участие в производстве и коммерциализации инноваций в формате взаимодействия «государство-наука-образованиебизнес».

В совокупности данные направления взаимодополняют друг друга и, таким образом, оживляют существующие механизмы поддержки отечественной науки и образования. Выпадение из системы того или иного элемента будет означать возникновение колебательных движений на пути выстраивания долгосрочных отношений между научными учреждениями, образовательными организациями, производственным сектором, государственными структурами и институтами развития для достижения высоких результатов совместной деятельности, и, как следствие, инновационного экономического развития.

В результате всего вышеизложенного, можно сделать следующий вывод.

Для обеспечения желаемых результатов в области инновационного экономического развития необходимо создание системы взаимодействия науки и образования. Основа лидерства страны в глобальной экономике ХХІвека лежит в целесообразной политике поддержания инноваций, направленное на воспроизводство интеллектуального капитала, в особенности, человеческого капитала.

В целом, при соблюдении рекомендаций из предложенный схемы научно-образовательная 
сфера России будет иметь неплохие стимулы для инновационного экономического развития. Тем не менее, необходимо рассматривать не только состояние научно-образовательной сферы путем «сверху-вниз», где главным участником и исполнителем модернизации научной и образовательной сфер является государство, и заявленные меры находят свое отражение, но и иметь в виду реальную действительность. Современная программа аспирантуры в России, весьма спорно выделенная в качестве третьей ступени высшего образования, теряет свое положение на мировой арене, негативно сказываясь на уровне развития отечественной научно-образовательной сферы и накладывая след на связующих процессах между наукой и образованием.

Конкурентоспособность научно-образовательной сферы определяется, прежде всего, тесными кооперационными связями между участниками инновационных процессов с помощью ряда административных мер, институциональных преобразований и кадрового воспроизводства науки и образования для достижения главной цели - создание единой траектории по инновационному пути развития экономики.

\section{Библиографический список}

1. Антология экономической классики. Т. 1 - М.: 1993.- с.308.

2. Гохберг Л. М. Наука и образование в России: пути интеграции. Вестник Финансовой академии. 2006. № 1-2 (37-38). С. 71-77.

3. Инновационная экономика. М.: ИД «ФОРУМ»- ИНФРА-М, 2014. 304 с.

4. Ключевский В.О. Афоризмы. Исторические портреты и этюды. Дневники / В.О.Ключевский.- Москва: Мысль, 1993.- 416 с.

5. Петти У. Экономические и статистические работы.- М.: Соцэкгиз, 1940. - 324 с.

6. Президент РАН: «Нам не нужна фабрика подготовки аспирантов» [Электронный ресурс] // Режим доступа: https://www.interfax.ru/interview/646078 (дата обращения: 20.08.2020).

7. Россия в цифрах, 2019: Краткий статистический сборник / Росстат-М, 2019-549 с.

8. Сажина М.А., Гаврилюк А.В. Интеллектуальная собственность в инновационной экономике: методологические аспекты. Научные исследования экономического факультета. Электронный журнал. 2020. Т. 12. № 2 (36). C. 26-39.

9. Сажина М.А. Управленческая экономика и поведенческая экономика: общее и особенное// Экономические науки, издательство Экон. науки (М.), № 10, с. 12-19.

10. Смит А. Исследование о природе и причинах богатства народов.-М.: Соцэкгиз, 1956, с. 490.

11. Communiqué of the Conference of Ministers responsible for Higher Education in Berlin on 19 September 2003[Электронный ресурс] // Режим доступа: http://www.ehea.info/page-ministerial-conference-berlin-2003 (дата обращения: 15.08.2020). 